\title{
ANTÓNIO DE BRUM FERREIRA
}

(1941-2013)

CARlos Alberto Medeiros ${ }^{1}$

O António de Brum Ferreira, um dos mais notáveis geógrafos portugueses do último meio século e um grande Amigo, deixou-nos fisicamente no dia 8 de Fevereiro de 2013. Sabia-se que, desde há algum tempo, se encontrava doente com gravidade. Contudo, no decurso dos pouco mais de dois longos anos em que sofrera os efeitos dessa enfermidade, o Brum - era mais fácil tratá-lo assim - decidira sem delongas restringir praticamente o convívio ao seu reduzido círculo familiar. Em circunstâncias dolorosas como a que viveu, a postura individual varia muito e, seja ela qual for, a melhor expressão de amizade e apreço consiste em respeitá-la. Algumas informações inevitavelmente filtradas davam conta da progressão do mal: mas foi com sobressalto que amigos, colegas, discípulos tiveram conhecimento súbito do desenlace ocorrido.

António de Brum Ferreira nasceu na povoação de Rabo de Peixe, situada na costa norte da ilha de S. Miguel, Açores, a 25 de Fevereiro de 1941. Os resultados brilhantes que alcançou na então chamada instrução primária fizeram desde logo prever o maior êxito no nível liceal que se seguia. Dificuldades de natureza vária, materiais sobretudo, condicionaram porém a paragem de um ano, até frequentar, com uma bolsa de estudo, o Liceu Nacional de Ponta Delgada, a partir de 1953. A atribuição da bolsa implicava classificações muito elevadas, o que pôs à prova a sua capacidade de trabalho, estimulada pelo gosto de estudar e pelo interesse despertado por grande parte das matérias tratadas. Foi no liceu que nos conhecemos e que se forjou entre nós uma sólida amizade, a qual depois se foi cimentando, no decurso da licenciatura e da carreira académica subsequente. Conhecia-o bem e posso testemunhar que, desde início, evidenciou um sentido de responsabilidade e uma dedicação ao estudo invulgares. A consciência que tinha da implicação das classificações obtidas na continuidade da bolsa de estudo, condicionou porventura a seriedade que sempre lhes atribuiu enquanto professor ou nos júris das provas académicas:

1 Professor Catedrático aposentado de Geografia, Universidade de Lisboa. 
ponderava-as com o maior cuidado e procurava garantir-lhes plena objectividade, sem nunca ceder a influências alheias ao real mérito daqueles que avaliava; dificilmente seria possível apontar-lhe qualquer descuido.

Terminado o curso liceal em Julho de 1960, ingressou na licenciatura em Geografia da Faculdade de Letras da Universidade de Lisboa. Note-se que, ao contrário do que acontece hoje, numa época em que as comunicações são rápidas, fáceis e frequentes, naqueles começos dos anos 1960 a passagem de S. Miguel para a «longínqua» Lisboa representava um verdadeiro choque na maneira de ser e de viver. Tudo era diferente, víamo-nos confrontados (o mesmo aconteceu comigo) com um ambiente alheio, desconhecido: a agitação nas ruas, os transportes, a vida nos cafés, a própria fala (a par de designações novas que nos confundiam - a bica, a imperial, o ardina, o puto, a moeda expressa em tostões - tínhamos de superar por vezes, em sentido inverso, a incompreensão de certos termos regionais nossos ou as consequências das particularidades de expressão impostas pelo inconfundível sotaque micaelense, particularmente cerrado, o do Brum). Nem tudo, porém, eram dificuldades: havia também a multiplicidade de manifestações culturais, as exposições, os grandes cinemas de então, o teatro e, muito em especial para o Brum (como para mim), a música, que tanto o atraiu por toda a vida. Não posso esquecer o nosso deslumbramento no S. Carlos, a representação da Aida de Verdi, a primeira de várias óperas a que, no decurso da licenciatura, e para além de concertos, fomos assistindo.

Ao cabo dos cinco anos do curso, que concluiu em Janeiro de 1966 com elevada classificação, o Brum, contratado como assistente, encontrava-se plenamente integrado no ambiente citadino que o acolhera. Relativamente ao leque multifacetado de domínios do conhecimento que a Geografia recobre, as suas preferências encaminhavam-no decisivamente para o da Geografia física. A dissertação de licenciatura escolhida, ainda que de âmbito mais amplo, uma monografia regional da ilha Graciosa, apontava já nesse sentido. A Graciosa é a ilha menos acidentada dos Açores, mas o seu relevo muito complexo suscita problemas diversos que proporcionaram a elaboração de um excelente primeiro capítulo da tese, ainda mais excelente se pensarmos que foi concebido por alguém que dava os primeiros passos na investigação científica. Com justificada satisfação, em 1987, numa reedição do seu trabalho, o Brum podia escrever: «Relendo o livro, é-me grato verificar que a interpretação geomorfológica, um dos aspectos mais difíceis da Geografia da ilha Graciosa, mantém-se, nas suas linhas gerais, actualizada e, até, confirmada pelas recentes descobertas geodinâmicas da região».

Guiado nos primórdios da sua carreira de investigador por Orlando Ribeiro, Mestre de sucessivas gerações de geógrafos, e por Suzanne Daveau, que deu um impulso fundamental nos estudos geográficos sobre o relevo e o clima entre nós, o Brum estagiou, pouco depois da obtenção do grau de licenciado, nas Universidades de Toulouse (Outubro de 1968 a Outubro de 1969) e de Clermont-Ferrand (Novembro de 1969 a Dezembro de 1970), tendo trabalhado na primeira com os professores F. Taillefer e J. Demangeot, na segunda com os professores A. Godard e M. Peterlongo. Deixou como testemunho da sua passagem por Toulouse a elaboração do traba- 
lho «Le relief du versant sud de la Montagne Noire», que veio a ser publicado em 1975 na Revue Géographique des Pyrénées et du Sud-Ouest. Estavam lançadas as sólidas bases da sua brilhante carreira como investigador e docente universitário, em particular no âmbito da Geomorfologia.

Não é este o lugar para lhe fazer referência detalhada, nem a orientação no sentido da Geografia humana de quem subscreve estas linhas permite tal objectivo. Mas alguns pontos devem ficar registados.

A dissertação de doutoramento, Planaltos e Montanhas do Norte da Beira. Estudo de Geomorfologia, foi apresentada em provas públicas no mês de Julho de 1978. Obteve a mais alta classificação e colheu referências muito elogiosas da crítica, tanto em Portugal como no estrangeiro. Para além do mais, representou um marco no quadro dos doutoramentos em Geografia: a última tese sobre o relevo de uma ampla área do território português, bem meritória aliás, havia sido a de Mariano Feio, relativa ao Baixo Alentejo e Algarve, e fora defendida pouco mais de um quarto de século antes. O trabalho de António de Brum Ferreira evidencia bem a renovação de conhecimentos entretanto havida, com recurso, por exemplo, à análise laboratorial dos depósitos existentes e à detecção remota.

No começo dos anos 1980 interessou-se pelo estudo da climatologia sinóptica, sublinhando a influência da circulação atmosférica em altitude nos estados do tempo à superfície do planeta; o interesse pelo tema está expresso num artigo sobre a seca de 1980-81, publicado no $n^{\circ} 35$ desta revista, em colaboração com Denise de Brum Ferreira, sua dedicada esposa, geógrafa também, que conhecera no estágio em Clermont-Ferrand. Seria ela que aprofundaria em particular esta linha de pesquisa, enquanto o Brum, renovando o seu gosto por temas de Geomorfologia, estudava a dinâmica actual das vertentes, trabalhava no âmbito da cartografia geomorfológica, analisava formas e formações periglaciárias. Este último tema deu origem à lição proferida com assinalável êxito nas provas de agregação, em Janeiro de 1989. Seguiu-se pouco depois o concurso para professor catedrático, em Abril de 1990.

Toda esta actividade científica se desenvolvia em paralelo com as tarefas docentes, às quais se entregava com entusiasmo equivalente. As suas aulas, enriquecidas por invulgar facilidade de expressão, eram um modelo de clareza, rigor e concisão. Orientou diversas dissertações de doutoramento, assegurou a formação de discípulos, abriu caminho para novas vias de investigação, pode dizer-se sem exagero que se fica a dever-lhe o principal impulso que nos últimos tempos conheceram em Portugal os estudos de Geografia física, particularmente os de Geomorfologia. Para além de actividades executivas, menos atraentes, no Departamento de Geografia da Faculdade de Letras e no Centro de Estudos Geográficos da Universidade de Lisboa, coube-lhe neste último, a partir de Janeiro de 1983, a direcção da Área de Investigação de Geografia física (cuja designação conheceu algumas alterações sucessivas de pormenor).

Foi também sócio fundador e primeiro presidente da Associação Portuguesa de Geomorfólogos, criada em 2000. E coube-lhe igualmente a condição de membro fundador do Centre Européen sur les Risques Géomorphologiques (Conselho 
da Europa, Estrasburgo); neste âmbito coordenou uma equipa portuguesa que colaborou em diversos projectos europeus, os quais deram origem a trabalhos publicados em revistas estrangeiras de nomeada.

Progressivamente, o Brum foi-se dedicando à elaboração de estudos com âmbito mais lato e diversificado. Quando me decidi a coordenar uma Geografia de Portugal desenvolvida, com a colaboração de 29 geógrafos, e que foi publicada em 4 volumes nos anos de 2005 e 2006, uma das condições que considerei indispensável foi a de que o Brum se encarregasse do primeiro volume, dedicado à Geografia física do território. Aceitou com entusiasmo e ele próprio redigiu todos os textos relativos à Geomorfologia. Tinha chegado à idade adequada, segundo me disse, para se abalançar a uma obra de síntese como essa. Trata-se de um trabalho valioso e foi para mim gratificante ouvir o Brum confessar que com muito gosto o tinha elaborado.

Sabia ser sincero no que dizia. Por outro lado, exigente em relação aos que com ele trabalhavam, rigoroso, por vezes impulsivo, era no fundo uma pessoa afável, com apurado sentido de humor, que se preocupava com os problemas de colegas e colaboradores, e procurava ajudá-los, sempre e em quaisquer circunstâncias. Sobretudo no decurso dos trabalhos de campo, a sua cordialidade natural manifestava-se bem, convivendo facilmente com todos e manifestando um entusiasmo exuberante - capaz de surpreender os que o rodeavam - quando detectava factos novos ou concretizava observações mais detalhadas. Caracterizava-o em particular uma profunda honestidade intelectual, que ditava a coerência das suas posições.

Em 2005 requereu e obteve a aposentação. Sem renegar contactos nem as relações cordiais que vinham de trás, optou por um modo de vida mais recolhido, bem de acordo afinal com as características do seu temperamento, restringindo o convívio frequente a um pequeno número de amigos. Tinha talvez razão Joel Serrão quando escreveu no preâmbulo do Elucidário Madeirense (edição de 1984) que «cada ilhéu é, por seu turno, uma pequena ilha...». Mas o amor pelo contacto com a Natureza não esmoreceu no Brum. Bem pelo contrário: continuou a percorrer o país em todos os sentidos, a fazer observações, a reunir apontamentos. Com tempo disponível, passou a ler muito mais, interessou-se por obras de diferentes géneros, mas apreciava muito fazê-lo ao ar livre, nalgum recanto mais acolhedor. Muitas vezes lhe gabei a comodidade do cadeirão onde me dedico à mesma actividade, mas nunca consegui convencê-lo. Muitas vezes também o incentivei a dar um arranjo, uma primeira elaboração aos novos materiais que ia colhendo, sem preocupações de eventual publicação, pelo simples gosto de o fazer, mas sempre me respondeu, mais ou menos convictamente, que não se sentia motivado para tal.

No final de 2010, o Brum soube que se encontrava gravemente doente. O abalo psicológico que sofreu foi profundo, terrível mesmo. Nada fazia prever o que aconteceu. Aquela força interior que o fazia interessar-se pelos mais variados assuntos, que o levava a empreender as longas caminhadas tão aliciantes para ele, encontrava-se afinal irremediavelmente comprometida. Mesmo assim, e passado um tempo, 
voltou a procurar refúgio na contemplação da Natureza, sempre que o ritmo dos tratamentos ou os estados do tempo o permitiam. Podia ao menos vislumbrar no horizonte os recortes das massas de relevo que se habituara a escalar e a analisar; recolhia exemplares das espécies vegetais que identificava e constituíam uma réplica das condições ambientais. Até que nos deixou: para os amigos, para aqueles que o estimavam ou admiravam, bem mais numerosos porventura do que pensava, restou um sentimento de vazio, de saudade, que permanecerá; e, sem esquecer a sua inestimável obra que perdura, os discípulos que renovadamente trilham vias de investigação que lhes abriu, ficou mais pobre a Geografia portuguesa. 